\title{
The Cost and Quality of Bottled Water in Refilling Stations and Tap Water in Cabanatuan City: A Comparative Study
}

\author{
Veronica A. Presentacion ${ }^{1}$, Ma. Victoria P. San Gabriel ${ }^{2}$, Merry Grace M. Nuñez ${ }^{3}$, \\ Geraldine A. Rimocal ${ }^{4}$, Harold M. Ramos ${ }^{5}$, Felipe E. Balaria ${ }^{6}$
}

\author{
${ }^{1}$ Cabanatuan City Water District, Nueva Ecija, Philippines \\ ${ }^{2}$ Department of Education - San Anton National High School \\ ${ }^{3}$ Central Luzon State University, Nueva Ecija, Philippines \\ ${ }^{4}$ Philippine Rice Research Institute, Nueva Ecija, Philippines \\ ${ }^{5}$ Local Government Unit - Bongabon, Nueva Ecija, Philippines \\ 1,2,3,4,5,6 Master in Business Administration, Nueva Ecija University of Science and Technology
}

Received: 30 May 2021; Received in revised form: 21 Jun 2021; Accepted: 01 Jul 2021; Available online: 10 Jul 2021

\begin{abstract}
This study compared the quality of tap water given by the Cabanatuan City Water District Prime Water Cabanatuan to replenished filtered water and bottled water obtained from water refilling stations. Water samples, in particular, had been tested in the lab for microbiological, physical, and chemical quality. Parameters include heterotrophic plate count, total coliform, thermotolerant coliform/Escherichia coli, total dissolved solids, $p H$, and turbidity. It was found that water supplied by Cabanatuan City Water District - Prime Water Cabanatuan City is cheaper, safe, and passed the Philippine National Standards for Drinking Water of 2017 compared to bottled water samples from refilling stations. However, despite the availability of potable water provided by the city water district, it is difficult to convince the public to adopt the behavior of drinking tap water instead of bottled or refilled purified water.
\end{abstract}

Keywords-Bottled water, comparative study, microbiological, refilled purified water, tap water.

\section{INTRODUCTION}

Water is required for the survival of living organisms and the planet's long-term viability. People will spend whatever it takes to get clean drinking water since it is a basic need for survival. The local corporate body that operates and maintains a water supply system in one or more provincial cities or municipalities is known as a water district or a water utility. "Residents and properties within the boundaries of water districts are responsible for acquiring, installing, improving, maintaining, and running water supply and distribution infrastructure for domestic, industrial, municipal, and agricultural applications and water districts are responsible for ensuring that their concessionaires have access to safe drinking water" [1]. However, the threat of contaminated water has always

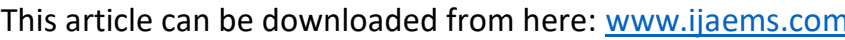

existed. Purchasing bottled water and drinking water from refilling stations has become a standard method of acquiring clean and safe drinking water in the Philippines. This condition exists not just in locations where water utility pipelines do not reach, but also in areas where water district service is provided. Some people use tap water for daily tasks and cleanliness, but they prefer bottled or purified water for drinking. According to new research from WHO and UNICEF, universal access to safe drinking water, sanitation, and hygiene is a human right included in the 2030 Sustainable Development Goals, but it can only be achieved if countries monitor and manage affordability (WHO, 2021) [2]. "The Philippine National Standards for Drinking Water are followed by local water districts and water refilling stations, and the latter is supervised by the Local Government Unit. Furthermore, only an enterprise 
with a current Food and Drug Administration (FDA) License to Operate (LTO) is permitted to prepare bottled water for trade or commercial distribution. (DOH AO 18A, 1993)" [3]. The use of purified water as a source of drinking water has increased over time (CCWD Customer Satisfaction Survey, 2006-2020) [4], and it is critical to quantify the economic impact on Cabanatuan City families. While there have been studies comparing the quality of tap versus bottled water, none have yet been conducted in the City of Cabanatuan to compare the quality and cost of bottled water sold in refilling stations to tap water supplied by the local water utility. The general objective of this research is to compare the quality and cost of tap water of Cabanatuan City and bottled water from refilling stations. Hence, a comparative study was conducted to describe the quality based on the current version of the Philippine National Standards for Drinking Water as to Microbiological Quality and PhysicalChemical Quality and compared the cost of refilled purified water, bottled water from water refilling stations, and tap water as drinking water

\section{METHODOLOGY}

This research used the quantitative research approach using the experimental design, comparing the quality of water, and comparing the cost. This research both utilized primary and secondary data. Primary data was collected from microbiological, physical, and chemical analysis results conducted by the researchers, while the secondary data is the current market cost of the drinking water. "In natural sciences and even in social sciences, quantitative research is based on the aspect of quantity or extent. It is related to the object that can be expressed in terms of quantity or something that can be counted" [ㄷ], thus a quantitative approach was used in this study. For microbiological, physical, and chemical analysis of water, a sample from one random water refilling station from each of Cabanatuan City Water District - Prime Water Cabanatuan City's 5 service areas, and one random tap water sample from a household from the same service areas. Samples from the water refilling stations are bought as bottled and as sold, while samples from tap water employed standard sampling procedures. All samples were analyzed at the CCWD Water Testing Laboratory. The comparison of the cost was based on the average price of purified water from refilling stations and the current rate of tap water in Cabanatuan City. Results of laboratory tests were evaluated based on the latest version of the Philippine National Standards for Drinking Water [6]. The cost of each type of drinking water and which costs less or more was presented using the costs collected from the Water Refilling Stations and the Local Water District current water rate [7]. Their costs were computed and compared according to the Daily Nutritional Guide Pyramid (Food and Nutrition Research Institute) [8]. for the number of water intake per person. Costs per household per month using the types of drinking water were compared as well based on the average household size in Nueva Ecija (Philippine Statistics Authority,2013) [9].

\section{RESULTS AND DISCUSSION}

\section{Microbiological Analysis}

Methods recommended in the Philippine National Standards for Drinking Water of 2017 and Standards Methods for the Analysis of Water and Wastewater 2nd Edition were employed [10]. A bottled water sample from water refilling station 4 failed in Heterotrophic Plate Count (HPC) analysis, the sample from water refilling station 2 failed in total coliform analysis, and sample from water refilling station 3 failed in all parameters including the presence of thermotolerant coliform /Escherichia coli. All samples from tap water passed within the microbiological standards of the PNSDW 2017.

Table 1. Microbiological Analysis Results

\begin{tabular}{lccc}
\hline \multicolumn{1}{c}{ Parameters } & $\begin{array}{c}\text { Heterotrophic } \\
\text { Plate Count }\end{array}$ & $\begin{array}{c}\text { Total Coliform } \\
\text { (CFU/mL })\end{array}$ & $\begin{array}{c}\text { Thermotolerant } \\
\text { Coliform / E.coli }\end{array}$ \\
\hline Sample ID & & $(\mathrm{MPN} / 100 \mathrm{~mL})$ \\
\hline Water Refilling Station 1 & 240 & $<1.1$ & $<1.1$ \\
\hline Water Refilling Station 2 & 250 & 2.6 & $<1.1$ \\
\hline Water Refilling Station 3 & 790 & $>8.0$ & $<8.0$ \\
\hline Water Refilling Station 4 & $>6500$ & $<1.1$ & $<1.1$ \\
\hline Water Refilling Station 5 & 27 & $<1.1$ & $<1.1$ \\
\hline
\end{tabular}

This article can be downloaded from here: www.ijaems.com 


\begin{tabular}{lccc}
\hline Tap Water 1 & $<1.0$ & $<1.1$ & $<1.1$ \\
\hline Tap Water 2 & $<1.0$ & $<1.1$ & $<1.1$ \\
\hline Tap Water 3 & $<1.0$ & $<1.1$ & $<1.1$ \\
\hline Tap Water 4 & 58 & $<1.1$ & $<1.1$ \\
\hline Tap Water 5 & 27 & $<1.1$ & $<\mathbf{1 . 1}$ \\
\hline PNSDW 2017 limits & $<\mathbf{5 0 0}$ & $<\mathbf{1 . 1}$ & \\
\hline
\end{tabular}

\section{Physical and Chemical Analysis}

PNSDW 2017 standard for $\mathrm{pH}$ and total dissolved solids (TDS) for water refilling stations is different from that of tap water. The $\mathrm{pH}$ value for water from refilling stations should be 5-7 while the TDS levels shall not exceed 10 $\mathrm{mg} / \mathrm{L}$ to validate the efficiency of the treatment process reverse osmosis or distillation process. Bottled Water samples from water refilling stations $1,2,4$, and 5 exceeded the standard levels for $\mathrm{pH}$. It should be considered that most water refilling stations market their product as alkali water. Bottled water samples from water refilling station 2 exceeded the standard for TDS, whereas all samples passed the standard limits for turbidity. All tap water samples from the distribution system passed within the PNSDW 2017 limits for pH, TDS, and Turbidity.

Table 2. pH, Total Dissolved Solids and Turbidity Analysis Results

\begin{tabular}{lccc}
\hline \multicolumn{1}{c}{ Parameters } & pH & $\begin{array}{c}\text { Total Dissolved } \\
\text { Solids }\end{array}$ & Turbidity \\
\cline { 2 - 4 } & & $\mathrm{mg} / \mathrm{L}$ & NTU \\
\hline Sample ID & & 9 & 0.19 \\
\hline Water Refilling Station 1 & 8.16 & 47 & 0.38 \\
\hline Water Refilling Station 2 & 8.07 & 8 & 0.30 \\
\hline Water Refilling Station 3 & 7.21 & 1 & 0.17 \\
\hline Water Refilling Station 4 & 8.31 & 8 & 0.18 \\
\hline Water Refilling Station 5 & 8.05 & $<\mathbf{1 0}$ & $<\mathbf{5 . 0}$ \\
\hline PNSDW 2017 limits & $\mathbf{5 . 0 - 7 . 0}$ & 175 & 0.38 \\
\hline Tap Water 1 & 8.39 & 181 & 0.51 \\
\hline Tap Water 2 & 7.35 & 366 & 0.39 \\
\hline Tap Water 3 & 7.56 & 186 & 0.24 \\
\hline Tap Water 4 & 7.32 & 194 & 0.41 \\
\hline Tap Water 5 & 7.36 & $<\mathbf{6 0 0}$ & $<\mathbf{5 . 0}$ \\
\hline PNSDW 2017 limits & $\mathbf{6 . 5 - 8 . 5}$ & & \\
\hline
\end{tabular}

\section{Cost Comparison}

\begin{tabular}{rccc}
\hline & per 500mL bottle & 19 Liters refill & $\begin{array}{c}\text { PRIME } \\
\text { WATER }\end{array}$ \\
\cline { 2 - 4 } PARAMETERS & Php & Php & Php \\
\hline Water Refilling Station 1 & 10 & 25 & \\
\hline Water Refilling Station 2 & 6 & 25 \\
\hline Water Refilling Station 3 & 10 & 25 \\
\hline Water Refilling Station 4 & 10 & 20
\end{tabular}

This article can be downloaded from here: www.ijaems.com 


\begin{tabular}{|c|c|c|c|}
\hline Water Refilling Station 5 & 10 & 25 & \\
\hline $\begin{array}{l}\text { Average Cost in water refilling } \\
\text { station }\end{array}$ & 9.2 & 24 & \\
\hline First 1000 Liters & & & 279.9 \\
\hline Cost per Liter & 18.40 & 1.26 & 0.28 \\
\hline \multicolumn{4}{|c|}{ Daily Nutritional Guide -8 glasses or 2 liters per person } \\
\hline Daily Cost Per person & 36.80 & 2.53 & 0.56 \\
\hline \multicolumn{4}{|l|}{ The daily cost of an Ave. Family } \\
\hline Size according to PSA & 184.00 & 12.65 & 2.80 \\
\hline $\begin{array}{l}\text { The monthly cost of an Ave. } \\
\text { Family Size according to PSA }\end{array}$ & $5,520.00$ & 379.50 & 84.00 \\
\hline
\end{tabular}

\section{Cost per Liter Comparison}

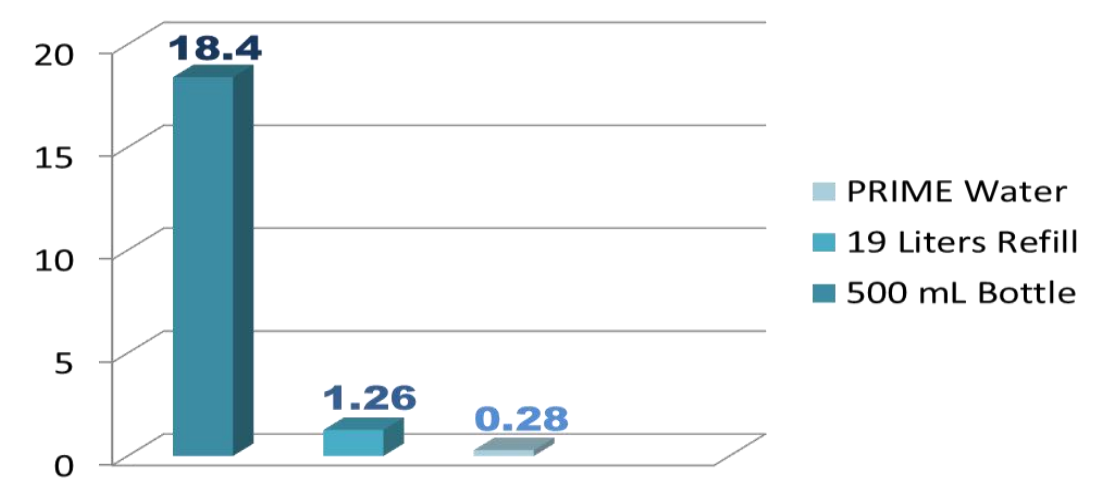

Fig.1: Cost per Litre Comparison

Figure 1 shows the cost comparison per liter of the three most common types of water consumed by the population. Based on the cost computed from the data available, the price of the $500 \mathrm{~mL}$ bottled water averaged from five refilling stations in Cabanatuan City scored the highest price with $\mathrm{P} 18.40$ per liter of consumption. The average cost per liter of 19 liters refilled water container was the second-highest among the three with P1.26 per liter and the cheapest one is the tap water provided by Prime Water with the cost of $\mathrm{P} 0.28$ per liter. 
Daily Nutritional Guide $\mathbf{- 8}$ glasses or 2 liters

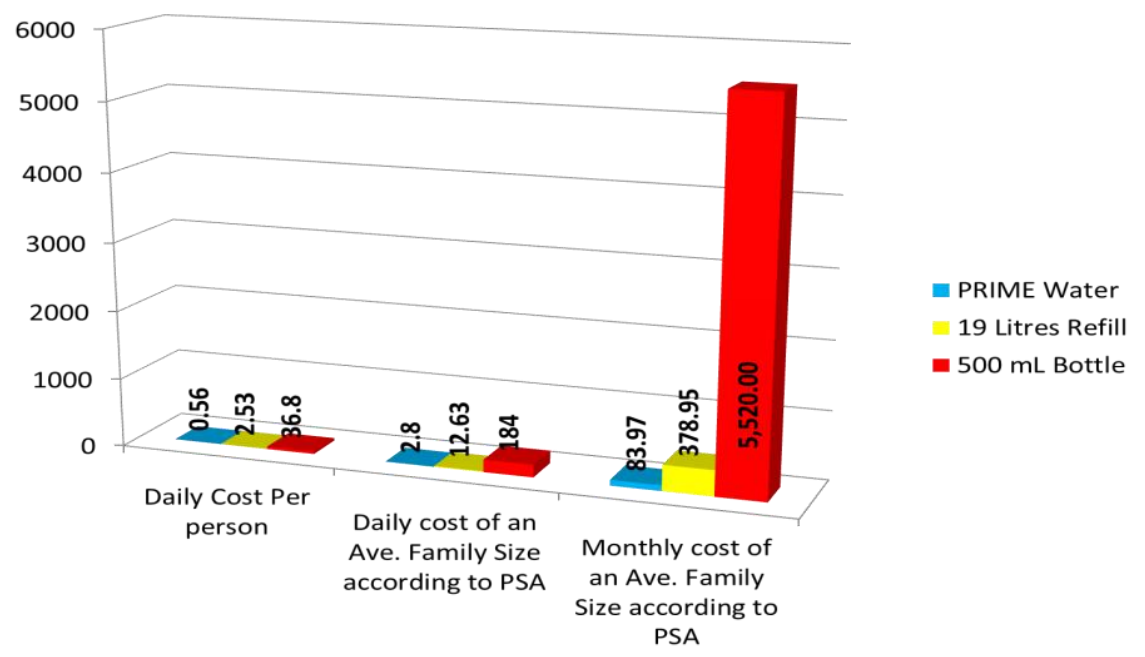

Fig.2: Cost Comparison Based on FNRI Daily Nutrition Guide

Figure 2 shows the price comparison between a single person's daily expense and average family size with five members daily and monthly expenses that goes to the drinking water if they follow the minimum amount of water intake suggested by the Food and Nutrition Research Institute guideline in drinking water which is at least 2 liters or 8 glasses a day. Like in figure 1, data showing the comparison of the daily cost a single person consumes, the $500 \mathrm{~mL}$ bottled water costs the highest with $\mathrm{P} 36.80$ for 2 liters of drinking water, followed by the 19 liters refill water container with $\mathrm{P} 2.53$ and the cheapest once again is the tap water provided by the PrimeWater with P0.56, which almost cost nothing compared to both $500 \mathrm{~mL}$ bottled water and 19 liters refill container. Following the same guideline used from the previous graph, data states that an average family with five members consuming two liters of water per person per day will have a $\mathrm{P} 184.00$ drinking water expense from $500 \mathrm{~mL}$ bottled water and P12.65 drinking water expense from 19 liters refill water container, while it will only cost them P2.80 drinking water expense provided by PrimeWater. Figure 2 shows the cost comparison that an average family pays for drinking water for a month. The graph shows the significant differences in cost per month between the three most common types of water consumed. Consuming tap water provided by PrimeWater will cost a family with five members only P84.00 per month which is so much cheaper compared to the remaining two. If we compare the P5,520.00 amount of $500 \mathrm{~mL}$ bottled water consuming family's cost with the PrimeWater consumer, we can see that the tap water consumer saves $\mathrm{P} 5,436.03$ which is a huge amount of money considering the current situation these days.

\section{CONCLUSIONS AND RECOMMENDATIONS}

Four bottled water samples sold at the 5 water refilling stations did not meet the $\mathrm{pH}$ limits set for water refilling stations. Three of the 5 samples did not meet the microbiological safety standards, and 1 of these 3 showed a positive result for the presence of both total coliform and thermotolerant coliform/E.coli, the indicator for fecal contamination. Potability of supplied drinking water by Cabanatuan City Water District - PrimeWater Cabanatuan City was demonstrated by conformity to the microbiological, physical, and chemical standards set by PNSDW. The cost of bottled water serve in every $500 \mathrm{ml}$ was the most expensive of all three categories. Based merely on the price that the water refilling stations are offering, the 19 liters water refillable containers are 14 times cheaper versus the $500 \mathrm{ml}$ bottled water. Cabanatuan City Water District - PrimeWater Cabanatuan City serves the cheapest drinking water. The researchers urge that the Local Government Unit implement water quality monitoring, for corporate social responsibility [11], particularly at water refilling stations that practice "Bottling," based on their findings and conclusions. Although the water may be safe and meet regulations after treatment, additional factors may have an impact on its safety once it is moved to containers. Cabanatuan City Water District - PrimeWater Cabanatuan City should also engage in public awareness campaigns about the safety of tap water and the economic impact on households, in order to address the declining use of tap water as an exclusive source of drinking water by Cabanatuan City concessionaires. Tap water is less expensive than water 
purchased at refilling stations, which will have a significant financial impact on customers and improved standard of living, particularly in regards to water safety [12].

\section{REFERENCES}

[1] Presidential Decree No. 198 May 25, 1973. Provincial Water Utilities Act of 1973

[2] World Health Organization. (n.d.). Affordability of WASH must be defined and tracked if 2030 Global Goals are to be met: new report. World Health Organization. https://www.who.int/news/item/03-05-2021-affordabilityof-wash-must-be-defined-and-tracked-if-2030-globalgoals-are-to-be-met-new report.

[3] Department of Health Administrative Order no. 18-A s 1993. Standards of Quality and Requirements for the Processing, Packaging and Labeling of Bottled Drinking Water. July 23, 1993

[4] Cabanatuan City Water District. Customer Satisfaction Survey 2006-2020

[5] Mishra, Dr. Shanti Bhushan \& Alok, Dr. Shashi. (2017). HANDBOOK OF RESEARCH METHODOLOGY.

[6] Department of Health Administrative Order no. 2017-0010. Philippine National Standards for Drinking Water 2017

[7] Cabanatuan City Water District, PrimeWater Cabanatuan City Approved Water Rates. December 1, 2019

[8] Food and Nutrition Research Institute. (n.d.). Daily Nutritional Guide Pyramid. FNRI Website. Retrieved May 25, 2021, from https://www.fnri.dost.gov.ph/index.php/tools-andstandard/nutritional-guide-pyramid\#adults-20-39yrs-old

[9] Philippine Statistics Authority. (2013, July 10). 2010 Population of Nueva Ecija is Larger by 295 Thousand Compared to Its 2000 Population (Results from the 2010 Census of Population and Housing). Philippine Statistics Office. https://psa.gov.ph/population-andhousing/node $/ 43726$

[10] American Public Health Association. (2012). Standard Methods for the Examination of Water and Wastewater. $22^{\text {nd }}$ Edition

[11] Mina, J.C., Barlis, P.T., Vega, N.C. and Subia, G.S. (2019) Corporate Social Responsibilities of Selected Resorts in Cabanatuan City, Nueva Ecija, Philippines. Open Access Library Journal, 6: e 5292. https://doi.org/10.4236/oalib.1105292

[12] Zabala Jr., B., Gutierrez, M. and Subia, G. (2018) Needs Assessment of Barangay Tanawan, Dingalan, Aurora towards a Proposed Oplan Development Program. International Journal of Environment, Agriculture, and Biotechnology, 3, 2163-2167. https://doi.org/10.22161/ijeab/3.6.28 